\title{
Esophageal Obstruction
}

National Cancer Institute

\section{Source}

National Cancer Institute. Esophageal Obstruction. NCI Thesaurus. Code C78279.

Blockage of the normal flow of the contents in the esophagus. 